\title{
EVALUATION OF THE EFFECTIVENESS OF MODERN COMMUNICATION CHANNELS DURING EMERGENCY SITUATIONS
}

\author{
MAMADOU OURY DIALLO, SHOGO AOKI, TOMOMI AOYAMA, KENJI WATANABE \\ Nagoya Institute of Technology, Japan
}

\begin{abstract}
Risk communication is a crucial component in the management of human-made and natural disasters. While traditional means of communications, such as television, radio and telephones etc. are widely used by governments and emergency response agencies for the purpose of disseminating risk information to at-risk populations, every time disasters strike, their reliability, efficiency and effectiveness are called into question. As a result, over the recent series of disasters that struck the world, modern communication mediums such as Facebook, Twitter, YouTube and others have emerged as important means for communicating with at-risks populations. However, though it is known that these mediums serve a variety of communication purposes, little research has examined the effectiveness of these modern communication channels during extreme conditions. This study is aimed at investigating the literature from the government perspective in order to evaluate the effectiveness of modern communication mediums for reaching at-risk populations in emergency situations. The review of the literature reveals that modern communication channels provide many opportunities to both response organizations and the affected communities. In addition, the effectiveness of modern communication mediums during emergencies is hampered by a number of factors, such as privacy and security, socio-economic conditions of users, operational issues, accuracy, and authentication problems that need to be addressed for these channels to deliver all their potential. Finally, the study concluded that regardless of the typology and intensity of the disaster, modern communication channels can be considerably effective if some measures are taken. Therefore, in light of that, the study made some recommendations for government.
\end{abstract}

Keywords: risk communication, communication channels, emergency situations, evaluation, modern communication platforms, disasters management, risk management.

\section{INTRODUCTION}

Across the world, there has been an increase of the number of both human-caused and natural disasters, from Hurricane Katrina to terrorist attacks in USA, earthquakes in Haiti and Asia, the tsunami in Indonesia, the earthquake and tsunami in Japan, and extremely cold winter in Europe [1]. Human-caused and natural disasters create a lot of uncertainties with devastating impacts resulting in a great need of communication since government and emergency management agencies, in order to reduce and mitigate damage, try to reach at-risk populations, who also seek to contact family and friends and also information regarding food, shelter and transportation as well [1]. Risk communication in the form of warning, alert messages, evacuation order, and health related information which enables people to make right and quick decisions is a crucial component of such time-critical situations' management. Communicating risk information requires effective communication channels. While traditional means of communications, such as television, radio and telephones etc. are widely used by governments and emergency response agencies for the purpose of disseminating risk information to at-risk populations, every time disasters strike, their reliability, efficiency and effectiveness are called into question. Modern communication platforms, which include Twitter, Myspace, Facebook, wikis, blog sites, and discussion forums, have been increasingly used during emergencies and disasters as a result. 
These new modern communication platforms are now being acknowledged by emergency responders, governments and non-governmental organizations as an integral tool for disaster management; and their importance emerged sharply as a powerful communication channel for emergency management [2], [3]. For instance, Social media sites rank as the fourth most popular source to access emergency information [4]. Modern communication platforms provide governments, response agencies, volunteer organizations, and affected populations the opportunity to communicate in an immediate and direct manner throughout the disaster relief efforts [5]. With these tools at hand, emergency response agencies can help populations develop and maintain situational awareness by communicating in realtime [6]. In addition, modern communication platforms also are efficient means for bidirectional flow of information between the public and the authorities in charge of public safety, and enhance citizen engagement by providing the citizens a canal through which they have the possibility to generate and disseminate their messages [7], [8].

Despite this, previous studies have shown that the role of modern platforms in the wake of natural disasters is still unclear, and that there is still a lack of systematic evidence on the effectiveness of using them as a coordination platform for disaster response [1], [9]. Moreover, very little is known about the efficacy of modern communication mediums in emergency and disasters related activity [10].

By conducting a survey of the literature, this study attempts to evaluate from the perspective of governments the effectiveness of SNS platforms for reaching at-risk populations in times of emergency in order to identify ways to optimize their use as risk communication tool through highlighting the advantages but also the challenges encountered during their practical usage in emergencies and disasters by authorities as well as how they were used. Then, recommendations were made to governments for addressing the identified obstacles.

\section{MODERN COMMUNICATION CHANNELS}

By modern communication channels, is intended any interactive digital communication combining the use of computers, tablets and mobile phones and internet-based applications devices or services, such as chat forums, blogs, search engines social media, and video streaming service. These new tools, characterized by the interactive and instantaneous communication they offer users in the form of visual, sound and text, have tremendously changed the way people communicate and interact. Today most of the conversations take place online, and the phenomena is likely to grow as one third of the global population is expected to be a social media user by 2020 [11].

\section{USE OF MODERN COMMUNICATION CHANNELS IN DISASTERS}

Disasters are known for their potential to disrupt the daily routine by damaging people lives and properties. A disaster is a time of extraordinary demand and urgency of information, where people try not only to develop and maintain situational awareness by seeking information in all directions, but also to communicate with their loved ones [12]. The fact that modern communication channels are almost the only channels available during disasters might be one of the reasons why modern communication mediums have increasingly been used during disasters in the recent years. As studies showed, when people feel a gap in their knowledge, they are likely to use whatever mean is available to them to fill the gap. However, in searching for information to fill the perceived deficiency of awareness, people associate familiarity with accessibility in sectioning the medium for filling that deficiency, because even people who have access to a medium may find that, if they are not familiar with it, they may not use it. 
Studies revealed that the public initiated the use of these modern communication channels in disasters before emergency responders, governments and non-governmental organizations [2]. Since then, modern communication channels have been playing an increasing role across the world in all kind of disasters. Thus, during the last decade, the use of these tools in disaster-events have attracted much attention from researchers, whose studies report on a considerable number of disaster and emergency cases where the mediums have been properly used in a variety of ways and for different purposes (Table 1).

Instances of innovative ways of using modern communication mediums have recently emerged. Following the 2010 Haiti Earthquake, online communication platforms made possible the coordination of worldwide communities' assistance efforts towards common goals by enabling the communication between all participants [2]. Interestingly, grasping the importance of their role in connecting people during disasters and crises, modern communication channels providing companies have developed special features and functions for emergency situations. During the Paris terrorist attack in 2015 which left 130 people dead and hundreds wounded [18], Facebook launched two functions: the "safety check" system, which allowed people who were in Paris at that time to inform their loved ones and family about their status, and the second function is that of support, which enabled people to show their support to the victims or France in general through their Facebook profiles.

Unfortunately, although modern communications mediums are seen as having succeeded where traditional communication channels have failed, it is wise to acknowledge that their use during emergencies has not always been successful. Some scholars call for a recognition and exploration of their technological limitations in reaching at-risk, vulnerable populations [1]. Examples like that of Katrina say a lot about the kind of situations technological failures can lead to. Marsha et al. examined the challenges the communication challenges encountered

Table 1: Ways and purposes of modern communication platforms usage in disasters.

\begin{tabular}{|c|c|c|c|c|}
\hline Case & Source & Receiver & Medium & Type of information/purpose \\
\hline \multirow{2}{*}{$\begin{array}{l}\text { Kumamoto } \\
\text { earthquake, } \\
2016\end{array}$} & $\begin{array}{l}\text { Mayor of } \\
\text { Kumamoto, Uto } \\
\text { City }\end{array}$ & Citizens & $\begin{array}{l}\text { Twitter, } \\
\text { Facebook }\end{array}$ & $\begin{array}{l}\text { Situation update, Request of on-site } \\
\text { photographs, misinformation caution, } \\
\text { request of volunteers, situational } \\
\text { update }\end{array}$ \\
\hline & Citizen & $\begin{array}{l}\text { Mayor of } \\
\text { Kumamoto }\end{array}$ & Twitter & $\begin{array}{l}\text { Provide on-site photos and address of } \\
\text { water leakage/disaster garbage }\end{array}$ \\
\hline $\begin{array}{l}\text { Brazos River } \\
\text { Flood, USA, } \\
2016\end{array}$ & $\begin{array}{l}\text { Fort Bend } \\
\text { County of OEM }\end{array}$ & Residents & $\begin{array}{l}\text { Facebook, } \\
\text { Twitter }\end{array}$ & $\begin{array}{l}\text { Alerts, health warnings, evacuation, } \\
\text { hazard map, call for damage } \\
\text { assessment, picture sharing, volunteers } \\
\text { and donations }\end{array}$ \\
\hline \multirow{4}{*}{$\begin{array}{l}\text { Great East } \\
\text { Japan } \\
\text { earthquake, } \\
2011\end{array}$} & Victims & $\begin{array}{l}\text { Tokyo } \\
\text { Governor }\end{array}$ & Twitter & $\begin{array}{l}\text { Request for rescue of victims who were } \\
\text { trapped in Kesennuma City, Miyagi } \\
\text { prefecture [13] }\end{array}$ \\
\hline & $\begin{array}{l}\text { Kesennuma City } \\
\text { Office }\end{array}$ & Citizen & Twitter & $\begin{array}{l}\text { Evacuation recommendation, Tsunami } \\
\text { alarm, instructions [14], [15] }\end{array}$ \\
\hline & Victims & Acquaintance & $\begin{array}{l}\text { Twitter, } \\
\text { Facebook }\end{array}$ & Safety confirmation [14], [15] \\
\hline & $\begin{array}{l}\text { Mayor of } \\
\text { Minami-Souma }\end{array}$ & The world & YouTube & $\begin{array}{l}\text { Requesting help, food and supplies for } \\
\text { his town [16] }\end{array}$ \\
\hline $\begin{array}{l}\text { The Victorian } \\
\text { bushfires, } \\
\text { Australia, } \\
2009\end{array}$ & $\begin{array}{l}\text { The Prime } \\
\text { Minister of } \\
\text { Australia }\end{array}$ & Public & Twitter & $\begin{array}{l}\text { Information on the fires, how to donate } \\
\text { money and blood, and where to seek } \\
\text { emergency help. [17] }\end{array}$ \\
\hline
\end{tabular}


by risk communicators, and found that one of the main factors was reaching residents in communities [19]. Then they concluded that, though the means of communication broke down as power outages were extended, the key factors that hindered the immediate dissemination of risk information to the affected areas were heavily reliant on electronic channels (e.g. websites), which prevented response organizations from having alternative plans in case of technological failures.

\section{PUBLIC USAGE VS GOVERNMENTS USAGE}

Modern communication channels have been playing an increasing role in disasters and emergencies. They are used for different purposes by a large number of actors, in particular governments and affected populations. According to Lindsay, modern communication platforms are used in disasters and emergencies in two ways: as an output to disseminate information and issue warnings, and as an input through incoming communication [20]. From a general point of view, these two ways give valuable insights about SNS. However, as communication needs and purposes are wide and varied, the way the public uses modern platforms in disrupting situations seems to differ in several ways from that of organizations and governments. Research shows that the public use SNS exclusively to a) develop and maintain situational awareness, b) give status and settings updates, c) keep up with their loved ones, d) request or provide assistance, and e) express emotions, opinions and sympathy [14], [21]. On the other hand, evidence suggests that government utilize SNS to a) provide the public with situational awareness updates, b) crowdsource, c) detect and combat misinformation and rumors, and d) Reassure and empathize with the public [1], [22]. During the Westgate mall attacks in Kenya in 2013, for instance, the authorities used social media to both disseminate information to the public and access information from the public by 'calling for information' and requesting the public to 'retweet their messages' [7]. A retweet is a way to republish a post that another Twitter user has written, to spread the word among your own Twitter followers. It is also a way to build a relationship with the original poster, who can easily see who has retweeted him or her [23]. Similarly, amidst the H1N1 outbreak in Fort Bend County in Texas, USA, in 2009, the Fort Bend County office of emergency management used Facebook, Twitter, and blogs to discredit and control rumors and speculations [24].

\section{ADVANTAGES}

The use of modern communication channels during human-caused and natural disasters provides significant opportunities to disaster response agencies, governments, and volunteer organizations that traditional media cannot provide. The advantages can be extensively summarized as follows:

\subsection{Providing and maintaining real-time situational awareness}

One of the requirements for response organizations to effectively cope with disasters is developing and maintaining situational awareness [25]. Developing and maintaining situational awareness requires two-way communications with timely flow of accurate, trustworthy and relevant information between emergency management agencies, governments, volunteer organizations and at-risk populations during all stages of disasters. Modern communication provides two-way communications as emergency management can disseminate information and also source information from the public [3]. Research pointed out the important role of providing and maintaining situational awareness that these channels play during extreme events through the provision of equal opportunity to all users to share 
timely information. For example, following the terrorist attacks that hit the Indian capital, Mumbai in 2008, the first news about the attacks were reported through social media by victims [26]. Similarly, first news about the Virginia Tech shooting in April 2007 came from students posting information from within their journalism class to a website [27].

\subsection{Stress management}

Emergency and disaster events generate a lot of uncertainties which lead to stressful situations. Naturally, when faced with hazardous situations that directly threaten their environment, possessions and loved ones like disasters, people tend to verse into a high state of concern [28]. Modern communication mediums make it possible for governments to help at-risk populations to cope with uncertainties by being engaged with them, and by reassuring them that the situation is under control. In so doing, governments give people the sense of being cared for and that they are not being let down.

\subsection{Support and disseminate big amounts of information to a large audience}

Modern communication means not only having the potential to provide and maintain situational awareness, but also the capacity to support intensive data usage with timely dissemination to a large number of audiences. For instance, only during the six-day period after Hurricane Sandy hit the US, Twitter registered 20 million tweets about Sandy, while 10 photos per second related to the Hurricane were reported being uploaded on Instagram [8].

\subsection{Response activities organization and coordination}

Recently, new ways of using modern communication platforms under extremes circumstances has emerged. Modern communication platforms are being used to organize and coordinate emergency response activities towards common goals. For example, studies reveal that, following the 2008 Sichuan earthquake, by posting a request for donations on Tianya forum, a relief foundation was able to receive over 6.3 million dollars from over 660,000 online individual donors within 10 days after the earthquake happened [9]. Further, similar trends were observed after the 2010 Haiti earthquake where social media served as platforms that allowed communities worldwide to provide assistance to the solicitous populations [2]. Likewise, research reports that community solutions appeared almost immediately following the floods that Australia experienced in 2011 [2].

\subsection{Understanding of public perceptions}

Modern communication platforms offer the opportunity to freely communicate. On these platforms, people can express their perceptions, emotions and attitudes without any restrictions. The opinions, exchanges and comments on these platforms during time-critical situations can help emergency management agencies understanding people risk perceptions and how their activities are perceived by the public. Researchers suggest that monitoring these patterns and themes over time could provide officials with insights into the perceptions and mood of the community, and their needs in relation to future disaster preparedness that cannot be collected through traditional methods [29]. 


\subsection{Recovery efforts}

Social media can play a vital role in recovery efforts in the aftermath of disasters and emergencies, especially when infrastructure must be rebuilt [1]. The huge amount of data shared by both the public and the authorities can be collected to estimate damages and accelerate the recovery phase. Further, these data can be used to evaluate actual disaster response plan and strategies in order to enhance future disaster preparedness.

\section{CHALLENGES}

Reducing and mitigating the damage of disruptive events on the society involve effective risk communication. The essential factors of effective risk communication are: (1) understanding characteristics of an audience; (2) defining how, when, and by whom a message is delivered impacts, and (3) adaptability to changing situations [30]. Although all the above listed components are essential for the risk communication, in this study, to evaluate the challenges related to the use of modern communication channels in emergency situations, attention will be given to these three elements: the information, the source and the channel. The reason is, first of all, information on modern communication platform can go far beyond the source's intended audience making it difficult to determine one's potential audience. Second, the effectiveness of a channel depends on its ability to satisfy the needs of its users, which are mainly sending and receiving information. In light of that, the main challenges in the use of modern communication platforms during extremes situations are identified and summarized below.

\subsection{Credibility challenges}

Previous studies have suggested that two important characteristics of information and sources are utility, meaning usefulness, relevance, timeliness, accessibility, and ease-of-use of information or of a source and credibility referring to trustworthiness, reliability and lack of bias of the information or of a source [31]. Credibility issues is major challenge in the use of modern communication channels in disaster situations. The challenge for emergency response organizations is how to validate, and ensure the accuracy of the crowd-sourced information before integrating it into their official sites since SNS users constantly produce vast amounts of information, both relevant and irrelevant [2], [8], [10]. In addition, it is not always possible to tell whether social media users are who they claim to be or whether the information they share is accurate [32]. In such conditions, distinguishing the trustful sources of information from the suspicious ones is a difficult task [8]. This remains a huge concern for authorities because if neglecting crowdsourcing may exclude important information, integrating the unofficial generated contents without ensuring their trustworthiness may cause serious damage to both response agencies' credibility but also to the public because research has shown that even when officials share unconfirmed information during emergencies, the information is still perceived to be more credible than information spread by regular citizens [33].

The scope and impact of rumors and misinformation on modern communication platforms confronts not only governments, but also researchers who are divided on the issue. For example, some researchers sustained that SNS are "self-regulating" as users tend to correct rumors and question inaccurate information [34], which other studies confirmed during the Westgate attack in Kenya as wrong photos posted were removed after approximately two days [7]. Despite this, a recent study found that rumors spread following the West Bank kidnapping could not be verified on any websites, challenging the idea that SNS regulate 
themselves [33]. Yet, the way governments managed the disasters that these two opposing views studied gives significant insights about the rectifying role that official information plays during emergencies. In the case of the studies where modern communication platforms exhibited the self-regulating characteristics, governments were regularly sharing information, which might have helped to correct misinformation, while in the second one, a gag order was issued and almost no official information filtered hindering the so-called "selfregulating" aspect. This suggests that an active official presence through regular and timely information sharing may significantly reduce rumors and misinformation. As scholars suggest, informal sources fill the gap left by formal sources [8].

In attempt to resolve the information credibility issue, Imran et al. studied the nature of social-media content generated during two different natural disasters, and proposed a model for extracting information from a socially-generated content. According to the authors, the model enables us to detect $40 \%$ to $80 \%$ of disaster-relevant information and generate an output that is correct $80 \%$ to $90 \%$ of the time. Finally, they concluded by sustaining that when information from similar locations converges into the same directions, this may be a strong indicator that the information is true [35]. Moreover, Facebook has recently launched a tool to fight against fake news.

\subsection{Structural, legal and organization challenges}

The proliferation of online communication platforms with different features over the last decades have left users with a variety of choices. With these platforms, anybody can be a content creator without being censored. During emergency situations, this can be a big issue for authorities given the real time and fast speed at which information containing contradicting and sensitive information endangering people's lives spreads through modern communication platforms which can be available to unwanted parties. For example, a study reported that during the Westgate Mall attack, the use of different and non-synchronized accounts by the Kenyan authorities made it difficult to follow the flow of information they shared. The same study presumed that the siege was prolonged because the public shared real-time information about the strategies and status of the security forces engaged in the response without any official control, which was used by the terrorist to enhance their position [7]. This uncontrollability nature of modern communication platforms was further confirmed during the kidnapping of Israeli teenagers in the West Bank in 2014 as the flow of information was not impacted despite a gag order [33]. This phenomenon is expected to grow out of control with the emergence of new features, such as 'live' on Facebook, which allows people to share live any event.

\subsection{Socio-economic conditions of the users and the technological limitations}

One other challenge over social media effectiveness in disaster is related to the socioeconomic conditions of at-risk populations. The use of online communication platforms requires users to be able to read, to have a functioning device and to have access to internet. That being said, less educated people, older people, and special needs populations, such as people with disabilities, and those in remote and less developed areas have more challenges in having access to these technologies, therefore making them vulnerable [10]. Also, even if these entire requirements are met, the infrastructure these new technologies rely on to be operational may be damaged during disasters and emergencies. In addition, in the research of Matti et al., of citizen's communication habits and use of SNS during crises and 
emergencies, interviewees expressed their concerns over blackout and over the fact that their phones being might be turned off or muted from time to time [21].

\subsection{Security and privacy concerns}

Different kinds of people are using SNS platforms for different purposes. During emergencies, information infringing the security and privacy of people can be divulged. In addition, some ill-disposed groups might intentionally provide inaccurate information to disrupt response efforts with the aim of perpetrating attacks [4].

\subsection{Conveniences and inconveniences of SNS platforms for emergency purposes}

Modern communication channels include a myriad of platforms ranging from micro-blogs to social media, such as Facebook, Myspace, WhatsApp, Twitter, Line and YouTube and so on. Although these platforms are similar in requiring internet, devices and electricity for functioning, but each of them are used for different task and needs based on the features and functionalities they offer to users. Thus, some of them are globally used and known more than others.

As shown by the review of literature, during disaster and emergency situations these mediums are used to perform a wide range of communication purposes. In addition, research suggests that each medium is used for specific communication and information sourcing needs. For example, scholars revealed that people: turned to blogs for emotional release and support, Twitter to find and distribute breaking news, and watched and posted YouTube videos specifically to view and share shocking disaster visuals [36]. Table 2 summarizes the way some modern communication platforms were used in disasters and emergency situations in order to identify how to best enhance SNS as risk communication tool in highly disruptive events.

\section{RECOMMENDATIONS}

To enable the optimum and effective use of modern communication platforms, some strategies are suggested below:

\subsection{Identify the platforms the public uses}

As shown in Table 2, there are many SNS platforms with different features. Factors such as cultural, regional and individual preferences influence the selection of these platforms. For example, WhatsApp is widely used in Israel, where Line and Twitter are popular in Japan, and Twitter is commonly used in Kenya. Identifying the platforms the public utilizes will help officials to ensure that they are on the right place and are using the right platforms.

\subsection{Create accounts on the identified platforms and synchronize them}

Having accounts on the same platforms as one's audience will guarantee official messages are reaching the intended audience. However, as the audience is diverse, it is likely that there will be more than one platform. Therefore, Odiogo, a software converting text message into audio files, can be practical for reaching special needs populations. For the harmony of the information shared across the identified platforms, a combination and synchronization of all the platforms will certainly be a plausible option. Such option helps to efficiently manage the numerous accounts by reducing the time and cost necessary to their management. SNS 
Table 2: Comparison chart of SNS platforms.

\begin{tabular}{|c|c|c|c|}
\hline Platform & Advantages & \multicolumn{2}{|c|}{ Inconveniences Illustrative case } \\
\hline YouTube & $\begin{array}{l}\text { Public, requires less reading skill, can } \\
\text { reach a large audience, effective for } \\
\text { preparedness and showing damage in } \\
\text { affected areas or urgent through instant } \\
\text { video sharing, popular [16] }\end{array}$ & $\begin{array}{l}\text { Less handy, non- } \\
\text { anonymous, not } \\
\text { interactive, heavy } \\
\text { data usage }\end{array}$ & $\begin{array}{l}\text { The Mayor of Minami-Souma, } \\
\text { appealing for help, food and supplies } \\
\text { to save his town, through YouTube } \\
\text { during the Great East Japan } \\
\text { Earthquake, Sakurai }\end{array}$ \\
\hline Twitter & $\begin{array}{l}\text { Effective for breaking news, allows } \\
\text { short and quick reporting where one } \\
\text { can receive tweets without having } \\
\text { access to their accounts, Handy, } \\
\text { anonymous, public, easy to track } \\
\text { information through hashtags, popular } \\
\text { [24] }\end{array}$ & $\begin{array}{l}\text { Limited characters, } \\
\text { misleading, } \\
\text { requires effective } \\
\text { communication } \\
\text { skill, less } \\
\text { interactive }\end{array}$ & $\begin{array}{l}\text { The city of Evanston, IL, USA } \\
\text { created an emergency Twitter page } \\
\text { from which any local resident with a } \\
\text { cell phone can receive tweets via text } \\
\text { messages }\end{array}$ \\
\hline Facebook & $\begin{array}{l}\text { Support more information (video, } \\
\text { document, PowerPoint, unlimited } \\
\text { characters), fast, available in many } \\
\text { languages, widely used, safety check } \\
\text { feature [24] }\end{array}$ & $\begin{array}{l}\text { Less handy, not } \\
\text { anonymous, fake } \\
\text { profiles }\end{array}$ & The Johnson County Emergency \\
\hline $\begin{array}{l}\text { Blogs and } \\
\text { Odiogo }\end{array}$ & $\begin{array}{l}\text { Provide space for sharing of } \\
\text { information and experiences. Widely } \\
\text { used, converts blog text into an audio } \\
\text { file, can reach a large audience } \\
\text { (disabled and illiterate people) [24] }\end{array}$ & $\begin{array}{l}\text { One way, can be } \\
\text { created by anyone }\end{array}$ & $\begin{array}{l}\text { Management, Kansas, and } \\
\text { Homeland Security Department }\end{array}$ \\
\hline Ushahidi & $\begin{array}{l}\text { Provide and disseminate information, } \\
\text { collects information from a group of } \\
\text { people in order to map crisis } \\
\text { information [37] }\end{array}$ & Less interactive & $\begin{array}{l}\text { Information on incidents of violence } \\
\text { and peace efforts during the } 2008 \\
\text { post-election in Kenya and elections } \\
\text { monitoring in Mexico and India. }\end{array}$ \\
\hline Myspace & $\begin{array}{l}\text { Quick dissemination and relatively } \\
\text { easy to use, interactive [38] }\end{array}$ & $\begin{array}{l}\text { Less used, mostly } \\
\text { popular for } \\
\text { entertainment }\end{array}$ & $\begin{array}{l}\text { During Hurricane Gustav, Myspace } \\
\text { developed a 'widget' for fast-track } \\
\text { disaster notification, finding } \\
\text { dislocated victims, }\end{array}$ \\
\hline Line & $\begin{array}{l}\text { Privacy, localize and guide to } \\
\text { evacuation sites, offer "Group Talk", } \\
\text { an emergency contact network [39] }\end{array}$ & $\begin{array}{l}\text { Less public, not } \\
\text { available in all } \\
\text { languages, not } \\
\text { widely used }\end{array}$ & $\begin{array}{l}\text { A call for evacuation of High school } \\
\text { students on LINE following the } \\
\text { flood at YAMAGUCHI, help to } \\
\text { evacuate local residents }\end{array}$ \\
\hline Flck & $\begin{array}{l}\text { Public, sharing picture and video, find } \\
\text { missing people }[40]\end{array}$ & $\begin{array}{l}\text { Not anonymous, } \\
\text { privacy and } \\
\text { security risk }\end{array}$ & $\begin{array}{l}\text { Help to find missing people during } \\
\text { the Southeast Asia Tsunami }\end{array}$ \\
\hline
\end{tabular}

management tools are a great way for that purpose. SNS management tools include Hootsuite, SEOFlx's, Sprout, and Buffer.

\subsection{Get the public know the official accounts}

Once the platform's identified, creating accounts and letting the public know them is the next step. Getting the public know the accounts require authorities to be active before, during and after disasters. One way to do this is through sharing regularly interesting and entertaining educational programs in any forms, especially before and after disasters. The aftermath of disasters is a very suitable time to enhance preparedness as people still recall the image of the disaster, which made their mind receptive to such kind of information. As discussed in the previous sections, official information helps to correct misinformation. When people know and are familiar with official accounts, rumors and misinformation are less likely to survive and harm people. 
7.4 Cooperate with software developing companies for more disaster-specific features

With close cooperation with software providing companies for more disaster-specific features, governments can explore regulatory ways to monitor, censor SNS contents, and also educate the general public about how to use SNS. Such initiative may help to tackle some issues related to privacy and security concerns.

\section{CONCLUSION}

In this study, the use of modern communication platforms in emergency situations has been examined. The review of the literature showed that these platforms offer more advantages than traditional communication channels do. The advantages are in terms of providing two-way communications, stress management, reaching large audience and connectedness. In addition, modern communication channels are great tools for both disseminating large amounts of information to a large audience and for gathering data from the audience. However, challenges and obstacles hindering their effectiveness have been identified as well. One of the major challenges is the credibility of information. Despite this, it is important to remember that the adoption of modern communication tools is no longer a choice, but a condition if emergency agencies want to convey their message to their audience, as these tools are one of the audience's preferred means of communicating and staying informed. Moreover, modern communication channels have proven to be more effective and efficient in terms of resistance to disruptions, and in terms of providing the possibility to develop continuous situational awareness and more importantly, for communicating with at-risks populations in order to help them reduce their exposure and vulnerability to hazardous and devastating situations.

Therefore, it is perfectly logical to argue that ingenious integration and combination of modern communication channels, consolidated by the traditional media can provide emergency response organizations with powerful and effective risk communication tools that, can certainly bring about a major change in the management of any kind of disaster whether of human or natural origin.

Finally, disaster and emergency situations have three clearly distinct phases: the preparation, response and recovery. Each phase is crucial for effective disaster management. The present study deals with only the response phase. Therefore, the next steps will be to complete whole process by developing framework for the preparation and the recovery phase.

Twitter account of the Mayor of Kumamoto

\section{APPENDIX}

Facebook account of the Uto city

Facebook account of Fort Bend County Office of Emergency Management

Facebook account of Facebook Safety

\section{REFERENCES}

[1] Velev, D. \& Zlateva, P., Use of social media in natural disaster management. Proc. of Economic Development and Research, 39, pp. 41-45, 2012.

[2] Simon, T., Goldbarg, A. \& Adini, B., Socializing in emergencies - A review of the use of social media in emergency situations. International Journal of Information Management, 35.5, pp. 609-619, 2015.

[3] Taylor, M. et al., The role of social media as psychological first aid as a support to community resilience building. Australian Journal of Emergency Management, 27.1(20), 2012. 
[4] Lindsay, B.R., Social media and disasters: Current uses, future options, and policy considerations, 2011.

[5] Goldfine, E., Best practices: The use of social media throughout emergency \& disaster relief, American University Washington DC, 2011.

[6] Anahi, A.L. \& Gregory, B., Social Media in Emergencies, 2013.

[7] Simon, T. et al. Twitter in the cross fire - the use of social media in the Westgate Mall terror attack in Kenya, 2014. 9.8:e104136.

[8] Hagar, C., Crisis informatics: Perspectives of trust - is social media a mixed blessing? SLIS Student Research Journal, 2.2(2), 2013.

[9] Qu, Y. et al., Harnessing social media in response to major disasters. CSCW 2011 Workshop: Designing Social and Collaborative Systems for China, 2011.

[10] Huang, C., Chan, E. \& Hyder, A.A., Web 2.0 and internet social networking: A new tool for disaster management? - Lessons from Taiwan. BMC medical informatics and decision making, 10.1(57), 2010.

[11] Statista, Statistics and facts about social media usage, Online. Available at: https://www.statista.com/topics/1164/social-networks/. Accessed on: 4 Mar. 2017.

[12] Black \& White Communications Inc., The Media and Public Trust in Natural Disaster: The Canadian Experience, 2000.

[13] Research Institute for Local Government, Online. Available at: http://www.rilg.or.jp/ htdocs/img/004/pdf/h24/h24 12 01.pdf. Accessed on: 12 Mar. 2017.

[14] Acar, A. \& Muraki, Y., Twitter for crisis communication: lessons learned from Japan's tsunami disaster. International Journal of Web Based Communities, 7.3, pp. 392-402, 2011.

[15] Social media in Emergency, Online. Available at: http://www.risktaisaku.com/articles/ print/210. Accessed on: 17 Mar. 2017.

[16] David, H.S., Keiko, N. \& Love, K., Social Media, Information and Political Activism in Japan's 3.11 Crisis, The Asia-Pacific Journal Japan Focus, Online. Available at: http://apjif.org/2012/10/24/David-H.-Slater/3762/article.html. Accessed on: 6 Mar. 2017.

[17] CNN iReport, Outstanding usages of Twitter, Online. Available at: http://ireport.cnn. com/docs/DOC-421155. Accessed on: 20 Mar. 2017.

[18] BBC NEWS, Paris attacks: What happened on the night? Online. Available at: http://www.bbc.com/news/world-europe-34818994. Accessed on: 4 Mar. 2017.

[19] Vanderford, M.L. et al., Emergency communication challenges in response to Hurricane Katrina: Lessons from the Centers for Disease Control and Prevention. Journal of Applied Communication Research, pp. 9-25, 35.1, 2007.

[20] Bruce, R. L, Social Media for Emergencies and Disasters: Overview and Policy Considerations, 2016.

[21] Haataja, M., Hyvärinen, J. \& Laajalahti, A., Citizens' Communication Habits and Use of ICTs During Crises and Emergencies. Human Technology, 2014.

[22] Beneito-Montagut, R. et al., Governmental social media use for emergency communication. In: proceedings of the 10th international conference on information systems for crisis response and management, Baden-Baden, Germany, 2013.

[23] Grauschopf, S., Retweets: What They Are and How to Use Them on Twitter, Online. Available at: https://www.thebalance.com/retweet-definition-what-retweet-meansand-how-to-use-them-896699. Accessed on: 21 Apr. 2017.

[24] Chavez, C. et al., A new way to communicate with residents: Local government use of social media to prepare for emergencies. Washington, DC International City/County Management Association, 2010. 
[25] Howitt, A.M., Managing crises: Responses to large-scale emergencies, ed. H.B. Leonard, CQ Press, 2009.

[26] Tinker, T.L., Dumlao, M. \& Mclaughlin, G., Effective social media strategies during times of crisis: Learning from the CDC, HHS, FEMA, the American Red Cross and NPR. Public Relations Strategist, pp. 25-39, 15.3, 2009.

[27] Palen, L. et al., Crisis informatics: Studying crisis in a networked world. In: Proceedings of the Third International Conference on E-Social Science, 2007.

[28] Stevens, I., Public oriented risk communication in the new risk Society, Ghent University, 2009.

[29] Kavanaugh, A.L. et al. Social media use by government: From the routine to the critical. Government Information Quarterly, pp. 480-491, 29.4, 2012.

[30] Janoske, M., Liu, B. \& Sheppard, B., Understanding risk communication best practices: a guide for emergency managers and communicators. START, National Consortium for the Study of Terrorism and Responses to Terrorism, University of Maryland, 2012.

[31] Robson, A. \& Robinson, L., Building on models of information behaviour: linking information seeking and communication. Journal of documentation, pp. 169-193, 2013.

[32] Merchant, R.M., Elmer, S. \& Lurie, N., Integrating social media into emergencypreparedness efforts. New England Journal of Medicine, pp. 289-291, 2011.

[33] Simon, T. et al., Kidnapping WhatsApp-Rumors during the search and rescue operation of three kidnapped youth. Computers in Human Behavior, pp. 183-190, 2016.

[34] Mendoza, M., Poblete, B. \& Castillo, C., Twitter Under Crisis: Can we trust what we RT? In: Proceedings of the first workshop on social media analytics, pp. 71-79, ACM, 2010.

[35] Imran, M. et al., Practical extraction of disaster-relevant information from social media. In: Proceedings of the 22nd International Conference on World Wide Web, pp. 1021-1024, ACM, 2013.

[36] Fraustino, J.D., Liu, B. \& Jin, Y., Social media use during disasters: a review of the knowledge base and gaps, 2012.

[37] Kasturi, K., role of social media in the disaster cycle, Online. Available at: https://www.linkedin.com/pulse/20140729164405-228313648-role-of-social-mediain-the-disaster-cycle.

[38] Connie, W., Linda, P., Jane, K., Starr, R.H. \& Murray, T., An Online Social Network for Emergency Management. Presented at 6th International ISCRAM Conference, Gothenburg, Sweden, 2009.

[39] Landgren, J. \& Jul, S., LINE official blog, Online. Available at: http://officialblog.line.me/ja/archives/54801265.html. Accessed on: 18 Mar. 2017.

[40] Flickr. Southeast Asia Tsunami-MISSING PERSONS, Online. Available at: https://www.flickr.com/groups/tsunami_help_missing/. Accessed on: 5 Mar. 2017. 